\title{
Antitumor activity of rhein lysinate against human glioma U87 cells in vitro and in vivo
}

\author{
JIN LIU ${ }^{1}$, KE ZHANG $^{2}$, YONG-ZHAN ZHEN ${ }^{3}$, JIE WEI $^{4}$, GANG HU $^{4}$, JUN-LING GAO $^{3}$, \\ YAN-XIA TIAN ${ }^{3}$ and YA-JUN LIN ${ }^{4}$
}

\author{
${ }^{1}$ College of Life Sciences, Beijing Normal University, Beijing 100875; ${ }^{2}$ Oncology Department, Rizhao City People's Hospital, \\ Rizhao, Shandong 276800; ${ }^{3}$ Key Laboratory for Chronic Diseases of Hebei Province, Key Laboratory for Preclinical and \\ Basic Research on Chronic Diseases of Tangshan City, School of Basic Medical Sciences, North China University \\ of Science and Technology, Tangshan, Hebei 063000; ${ }^{4}$ The Key Laboratory of Geriatrics, Beijing Hospital \\ and Beijing Institute of Geriatrics, Chinese Ministry of Health, Beijing 100730, P.R. China
}

Received October 9, 2015; Accepted November 12, 2015

DOI: $10.3892 /$ or.2015.4518

\begin{abstract}
In previous studies, we demonstrated that rhein lysinate (RHL), the salt of rhein and lysine that is easily dissolved in water, inhibited the growth of tumor cells derived from breast and ovarian cancer, hepatocellular carcinoma, cervical cancer and lung carcinoma. Based on these observations, human glioma U87 cells and a xenograft model in BALB/c nude mice were used to examine the antitumor activity of RHL against human glioma. Notably, RHL statistically significantly suppressed the growth of human glioma U87 xenografts in BALB/c nude mice. In vitro, there was a significant reduction in cell proliferation after treatment with RHL in a dose- and time-dependent manner. The overall growth inhibition was correlated with the increase in reactive oxygen species (ROS) production and cell apoptosis. The apoptosis- and cell cycle-related proteins including BAX and Bim were increased, whereas Bcl-2 and cyclin D were decreased in the RHL-treated cells. The results demonstrated that RHL is highly effective against the growth of human glioma U87 xenografts in BALB/c nude mice. The potent antitumor activity of RHL may be mediated through downregulation of Bcl-2 and cyclin D expression and upregulation of BAX and Bim expression.
\end{abstract}

\section{Introduction}

Malignant gliomas are characterized by aggressive tumor growth with a mean patient survival of 15-18 months and frequently develop resistance to temozolomide (TMZ) which is the first-line treatment for patients with high-grade gliomas $(1,2)$. Although TMZ has been well demonstrated to

Correspondence to: Professor Ya-Jun Lin, The Key Laboratory of Geriatrics, Beijing Hospital and Beijing Institute of Geriatrics, Chinese Ministry of Health, Beijing 100730, P.R. China

E-mail: linyajun2000@126.com

Key words: rhein lysinate, human glioma, apoptosis, tumor inhibition effectively prolong the survival of patients with brain tumors in clinical application, unfortunately, glioma cells showed resistance to TMZ in certain cases (3-6). Therefore, current therapy is far from satisfactory, indicating the need for new therapeutic agents and approaches which can prolong the survival of glioma patients.

Recently, extensive study has been conducted to evaluate the therapeutic efficacy and safety of natural compounds for treating cancer. Rhein (4,5-dihydroxyanthraquinone-2-carboxylic acid) is a natural product derived from the rhizome of rhubarb which has been used medicinally in China for more than 1,000 years (7). Rhein possesses diverse biological properties such as antioxidant $(8-10)$, anti-inflammatory $(11,12)$, antiviral (13), antibacterial (14), antifungal (15), antiallergic (16) and anticancer (17-24). The reported mechanism of the antitumor activity of rhein in cancer cells is due to its ability to induce apoptosis and/or cell cycle arrest in corresponding cancer cells $(20,21)$. Although rhein has many pharmacological effects, due to its inability to dissolve in water, the use of rhein in the clinic is limited.

Our previous studies showed that rhein lysinate (RHL), the salt of rhein and lysine that is easily dissolved in water, inhibited the proliferation of breast (25) and ovarian cancer (26), hepatocellular carcinoma (26), cervical cancer $(27,28)$, and lung carcinoma cells (29), and human umbilical vein endothelial cells (HUVECs) (28). However, the $\mathrm{IC}_{50}$ was found to be higher in normal cells, meaning that the drug can be used to prevent the proliferation of cancer cells at a lower concentration, without a strong effect on normal cells. Yet, its effect on human glioma is still unknown.

In the present study, human glioma U87 cells and a xenograft model in BALB/c nude mice were used to examine the antitumor activity of RHL against human glioma, supporting the potential use of rhein as an anti-glioma medicinal agent.

\section{Materials and methods}

Chemicals and reagents. Rhein (purity, 98\%) was purchased from Nanjing Qingze Medicine Ltd. (Nanjing, Jiangsu, China), 
while lysine was purchased from Beijing Solarbio Science and Technology Co. (Beijing, China). RHL was produced at the Department of Oncology of the Institute of Medicinal Biotechnology, the Chinese Academy of Medical Sciences (patent no.200810089025.8).3-(4,5-Dimethylthiazol-2-yl)-2,5diphenyltetrazolium bromide (MTT) and dimethylsulfoxide (DMSO) were obtained from Sigma-Aldrich (Shanghai, China). Dichlorodihydrofluorescein-diacetate (DCFH-DA) was obtained from Molecular Probes (Eugene, OR, USA). Antibodies targeting Bcl-2, BAX, Bim, cyclin D and $\beta$-actin were purchased from Santa Cruz Biotechnology, Inc. (Santa Cruz, CA, USA). Secondary antibodies against rabbit or mouse IgG were purchased from Cell Signaling Technology (Danvers, MA, USA). The prestained protein marker p7708V was purchased from New England Biolabs Ltd. (Beijing, China). All other chemicals were of standard analytical grade.

Cell culture. The human glioma U87 cell line was cultured in RPMI-1640 medium (Gibco-BRL, Grand Island, NY, USA) supplemented with $10 \%$ heat-inactivated fetal bovine serum (Sigma Chemical Co., St. Louis, MO, USA), $100 \mathrm{U} / \mathrm{ml}$ penicillin and $100 \mu \mathrm{g} / \mathrm{ml}$ streptomycin at $37^{\circ} \mathrm{C}$ in a humidified atmosphere containing $5 \% \mathrm{CO}_{2}$. The human glioma U87 cell line was obtained from the Cell Center of the Institute of Basic Medical Sciences, Chinese Academy of Medical Sciences and Peking Union Medical College (Beijing, China).

In vivo therapeutic effects. Fourteen female BALB/c nude mice $(20 \pm 2 \mathrm{~g})$ obtained from Vital River Laboratories (Beijing, China), at the age of 4-6 weeks were used for human glioma U87 xenografts. Mice were maintained in a temperature-controlled room $\left(22 \pm 2^{\circ} \mathrm{C}\right)$ with a 12 -h light/12-h dark cycle and a relative humidity of $40-60 \%$. The mice were given ad libitum access to food and water. All animal experiments were approved by the Institutional Animal Care and Use Committee of Beijing Normal University. U87 tumors for implantation were initially grown by injection of U87 cells at a dose of $5 \times 10^{6}$ cells/mouse in two female BALB/c nude mice. A tumor piece of $2-3 \mathrm{~mm}$ in diameter was implanted subcutaneously into each experimental animal. After 9 days of tumor growth, the animals were randomly divided into groups $(n=6)$ in a manner that minimized the difference in tumor size between the groups. Each animal received $200 \mu \mathrm{l}$ of either phosphate-buffered saline (PBS) (vehicle control) or RHL by intraperitoneal injection every other day for a consecutive 14 days. At the end of the experiment, the body and tumor weight were measured.

Cell proliferation assay. Cell proliferation assays were performed using the MTT method, according to the manufacturer's instructions. The cells were seeded into 96-well plates (Costar, Cambridge, MA, USA) with 3,000 cells/well. Subsequent to overnight incubation, triplicate wells were treated with various concentrations of RHL $(0,20,40,80$ and $160 \mu \mathrm{mol} / \mathrm{l})$ for $48 \mathrm{~h}$. Next, $20 \mu \mathrm{l}$ of MTT solutions $(5 \mathrm{mg} / \mathrm{ml}$ in PBS) were added to each well and incubated for $4 \mathrm{~h}$ at $37^{\circ} \mathrm{C}$. The MTT formazan was dissolved in $150 \mu \mathrm{l}$ DMSO and the absorbance was measured with a microplate reader (Multiskan MK3; Thermo Labsystems, Waltham, MA USA) at a wavelength of $570 \mathrm{~nm}$.
Cell growth curve. Cells were plated into 96-well plates at a density of 500 cells/well. Six plates were seeded with cells. Triplicate wells/plate were treated with various concentrations of RHL $(0,20,40,80$ and $160 \mu \mathrm{mol} / \mathrm{l})$. One plate was assayed by MTT method as described above each day until the sixth day. The cell growth curve for various concentrations of RHL was constructed.

Detection of reactive oxygen species (ROS) by DHCF-DA. Intracellular hydrogen peroxide levels were monitored by fluorescence microscopy and flow cytometry after staining with DCFH-DA. Cells were plated at 250,000 cells/flask. Following a 24-h incubation period, the cells were treated with various concentrations of RHL $(0,20,40,80$ and $160 \mu \mathrm{mol} / \mathrm{l})$. Forty-eight hours later, DCFH-DA $(10 \mu \mathrm{mol} / \mathrm{l})$ was then added to each flask. After a 1-h incubation period, the cells were monitored using an Olympus inverted fluorescence microscope (Tokyo, Japan), and were subjected to flow cytometric analysis with FACSCalibur and CellQuest software (Becton-Dickinson, Franklin Lakes, NJ, USA). The percentage of cells displaying increased dye uptake was used to reflect an increase in ROS levels.

FITC-Annexin V/PI apoptosis assay. Cells were plated at 250,000 cells/flask. Following a 24-h incubation period, the cells were treated with various concentrations of RHL $(0,20$, $40,80$ and $160 \mu \mathrm{mol} / \mathrm{l})$. Forty-eight hours later, the cells were collected and resuspended in $200 \mu 1$ binding buffer. Then, $10 \mu \mathrm{l}$ FITC-labeled enhanced Annexin V and $10 \mu \mathrm{l}$ propidium iodide (PI) were added. Upon incubation in the dark (15 min at room temperature or $30 \mathrm{~min}$ at $4^{\circ} \mathrm{C}$ ), the samples were diluted with $300 \mu \mathrm{l}$ binding buffer. Cells were subjected to flow cytometric analysis with FACSCalibur and CellQuest software.

Western blot analysis. Cells were harvested and washed with PBS. The whole cellular extracts were prepared by incubating cells on ice in a lysis buffer and a cocktail of phosphatase inhibitors (Roche, Indianapolis, IN, USA). The cell lysates were cleared by centrifugation at $12,000 \mathrm{x}$ g for $20 \mathrm{~min}$. Protein concentrations were determined by Bradford assay. Equal amounts of lysate $(40 \mu \mathrm{g})$ were resolved by SDS-PAGE and transferred to polyvinylidene difluoride membranes (Millipore Corp., Bedford, MA, USA). The membranes were blocked in TBST containing $5 \%$ non-fat skim milk at room temperature for $2 \mathrm{~h}$ and probed with primary antibodies overnight at $4^{\circ} \mathrm{C}$. Then the membranes were blotted with an appropriate horseradish peroxidase-linked secondary antibody (Santa Cruz Biotechnology). Proteins were visualized using enhanced chemiluminescence western blotting detection reagents (Amersham Pharmacia Biotech, Inc., Piscataway, NJ, USA).

Statistical analysis. Results are expressed as the means \pm SD. Treatment effects were compared using one-way ANOVA and differences between the means were considered to indicate a statistically significant result when $\mathrm{P}<0.05$.

\section{Results}

Inhibition of human glioma U87 xenograft growth in BALB/c nude mice. Treatment was started on day 9 after tumor 
A

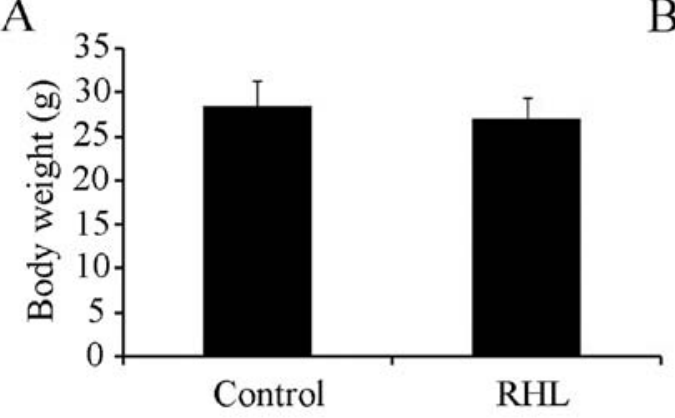

B

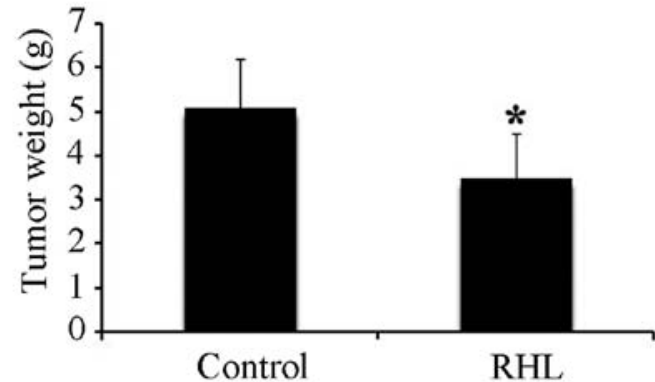

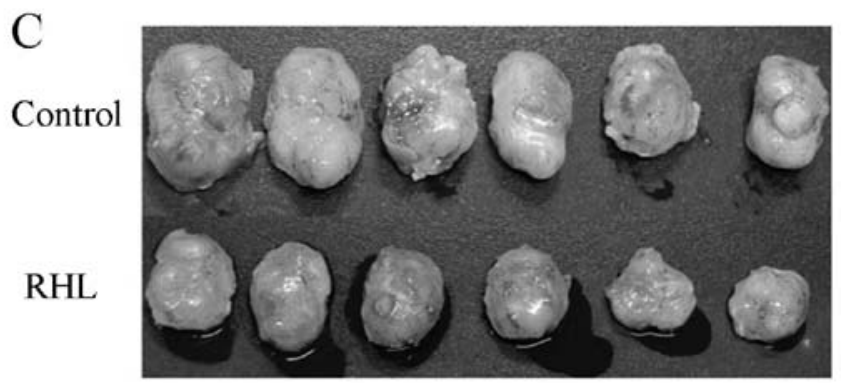

Figure 1. Effects of rhein lysinate (RHL) on the growth of human glioma U87 xenografts in BALB/c nude mice. Each animal was intraperitoneally administered with $200 \mu \mathrm{l}$ of either PBS (vehicle control) or RHL every other day for consecutive 14 days after tumor transplantation. ${ }^{*} \mathrm{P}<0.05$, compared with the control group. (A) Body weight, (B) tumor weight, (C) images of the tumors.

transplantation. RHL was administered by intraperitoneal injection at doses of $50 \mathrm{mg} / \mathrm{kg}$ every other day for consecutive 14 days. Control mice were administered PBS vehicle only. The body weight of the animals showed no significant differences between the control and treated groups (Fig. 1A). The growth of tumors in the RHL-treated BALB/c nude mice was significantly suppressed compared with the controls (Fig. 1B and C). Treatment with RHL inhibited the growth of human glioma U87 xenografts by $31.9 \%$. These findings suggest that RHL at a well-tolerated dose markedly inhibited tumor growth.

Growth inhibition of RHL in human glioma U87 cells. The growth inhibitory effect of RHL on human glioma U87 cells was examined with MTT assay. Cells were cultured for $48 \mathrm{~h}$ (Fig. 2A) in the presence of various concentrations of RHL. The U87 cells showed a decreased cell proliferation in a dose-dependent manner after treatment with RHL. In addition, RHL $(160 \mu \mathrm{mol} / \mathrm{l})$ inhibited the proliferation of the U87 cells by $40 \%$ at $48 \mathrm{~h}$. Compared with the control group, RHL at 20 and $40 \mu \mathrm{mol} / 1$ inhibited $\mathrm{U} 87$ cell proliferation on day 6 . Nevertheless, RHL at 80 and $160 \mu \mathrm{mol} / 1$ inhibited U87 cell proliferation from initial administration (Fig. 2B)

Induction of apoptosis by RHL in human glioma U87 cells. Induction of apoptosis by RHL was confirmed by FITC-Annexin V/PI staining. RHL at $80 \mu \mathrm{mol} / 1$ induced apoptosis in the glioma U87 cells. The ratio of apoptosis was significantly enhanced when cells were incubated with $160 \mu \mathrm{mol} / 1 \mathrm{RHL}$ for $48 \mathrm{~h}$. This suggested that apoptosis was the predominant mode of RHL-induced cell death (Fig. 3).

Induction of ROS production by RHL in human glioma U87 cells. Induction of ROS production by RHL was confirmed by DCFH-DA staining and detected by fluorescence
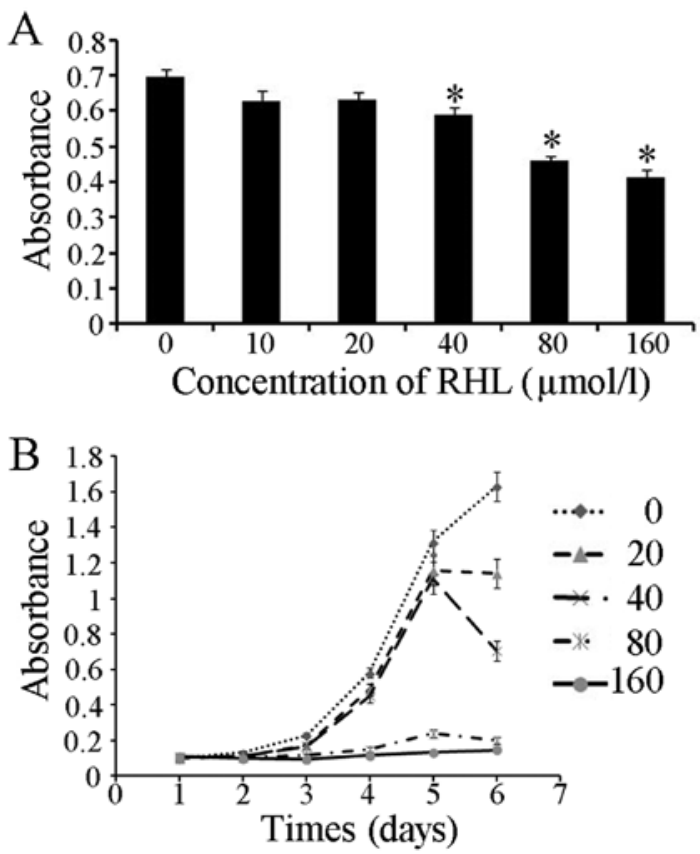

Figure 2. (A) Growth inhibition of human glioma U87 cells by RHL. Cells were exposed to rhein lysinate (RHL) at various concentrations for $48 \mathrm{~h}$ and proliferation was determined by MTT. (B) Growth curve of human glioma U87 cells treated with RHL. Cells were exposed to RHL at various concentrations for a consecutive 6 days and proliferation was determined by MTT each day. Data are from three independent experiments. ${ }^{*} \mathrm{P}<0.05$, compared with the control group.

microscopy and flow cytometry. Fluorescence intensity/cell was significantly enhanced when cells were treated with RHL for $48 \mathrm{~h}$ in dose-dependent manner. This suggested that RHL induced ROS production in a dose-dependent manner in glioma U87 cells (Fig. 4). 

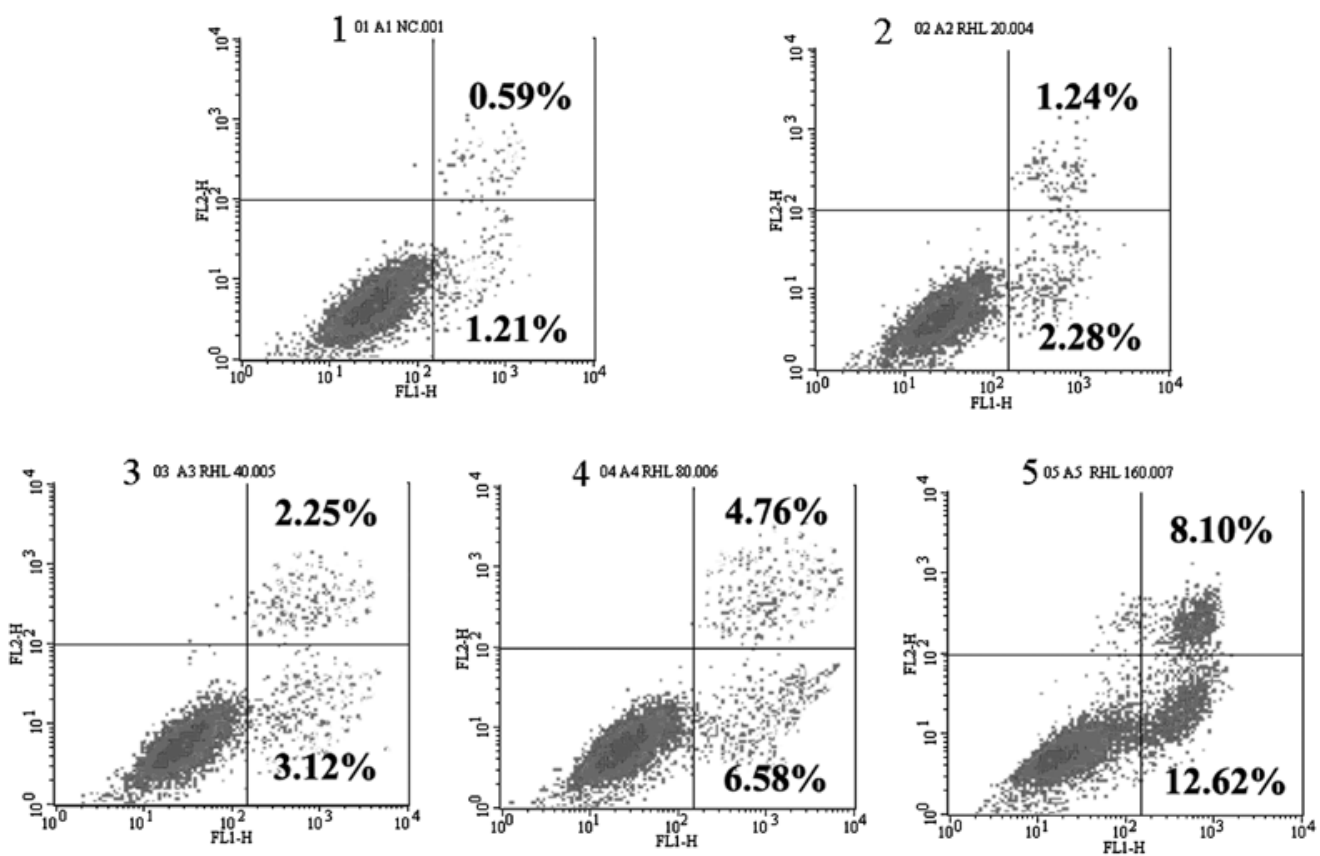

Figure 3. Induction of apoptosis by rhein lysinate (RHL) in human glioma U87 cells. Cells were treated with RHL for $48 \mathrm{~h}$ at the indicated concentrations (1, $0 \mu \mathrm{mol} / 1 ; 2,20 \mu \mathrm{mol} / 1 ; 3,40 \mu \mathrm{mol} / 1 ; 4,80 \mu \mathrm{mol} / 1 ; 5160 \mu \mathrm{mol} / 1 \mathrm{RHL})$. Cells were labeled with a combination of FITC-Annexin V and PI followed by flow cytometric analysis. The percentage of apoptotic cells (upper right quadrant and lower right quadrant) is indicated.
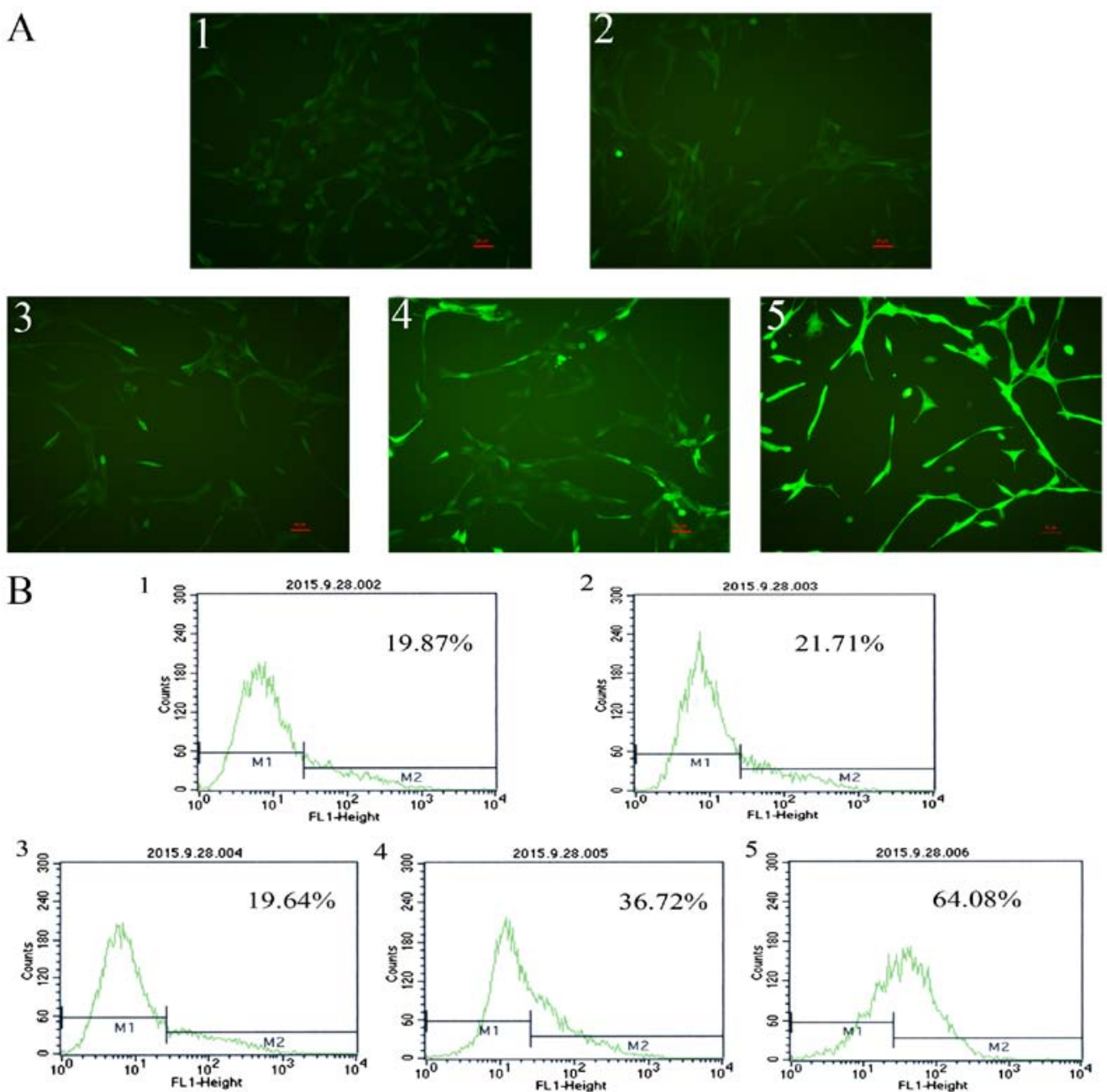

Figure 4. Induction of ROS production by rhein lysinate (RHL) in human glioma U87 cells. Cells were treated with RHL for $48 \mathrm{~h}$ at the indicated concentrations $(1,0 \mu \mathrm{mol} / 1 ; 2,20 \mu \mathrm{mol} / 1 ; 3,40 \mu \mathrm{mol} / 1 ; 4,80 \mu \mathrm{mol} / 1 ; 5,160 \mu \mathrm{mol} / 1 \mathrm{RHL})$. Cells were labeled with DCFH-DA followed by inverted fluorescence microscopy (A) and flow cytometric analysis (B). The percentage of DCFH-DA-positive cells is indicated. 

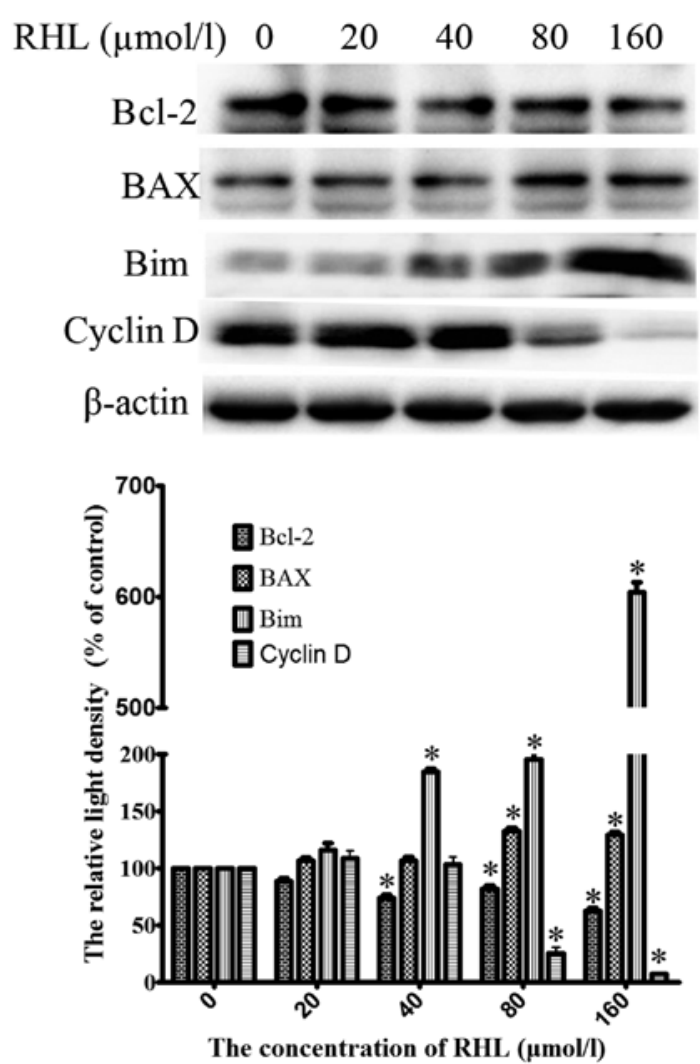

Figure 5. Effect of rhein lysinate (RHL) on the expression of proteins associated with apoptosis and the cell cycle. Cells were treated with RHL at different concentrations for $48 \mathrm{~h}$ and then lysed and subjected to western blotting as described in Materials and methods. ${ }^{*} \mathrm{P}<0.05$, compared with the control group.

Downregulation of Bcl-2 and cyclin D and upregulation of $B A X$ and Bim in the RHL-induced apoptosis in glioma U87 cells. In order to investigate the mechanism of RHL against human glioma U87 cells, we examined whether RHL treatment modulates the levels of apoptosis-associated and cell cycle-associated proteins. As shown in Fig. 5, expression of Bcl-2 was markedly downregulated by RHL treatment in the U87 cells, whereas the levels of BAX and Bim were increased. In addition, we also examined the expression of cyclin $\mathrm{D}$. The level of cyclin D was decreased after RHL treatment.

\section{Discussion}

Malignant glioma is one of the most deadly human malignancies worldwide and its incidence has increased in recent years (30). In spite of the progress in the prognosis and treatment of glioma, the dismal outcome has not improved substantially over the last three decades. The survival of glioma patients is still quite short, particularly when invasion and metastasis occur, even when aggressive surgical resection, chemotherapy, and radiotherapy are carried out. Temozolomide (TMZ) is a well-tolerated orally bioactive alkylating agent used in glioma patients which has been adopted as the first-line treatment in patients with high-grade gliomas. Although TMZ has been well demonstrated to effectively prolong the survival of brain tumor patients in clinical application $(1,2)$, unfortunately, glioma cells show resistance to $\mathrm{TMZ}$ in some cases (3-6). Therefore, new therapeutic agents and approaches are highly required for prolonging the survival of glioma patients.

Our previous studies showed that rhein lysinate (RHL), the salt of rhein and lysine that is easily dissolved in water, inhibited the proliferation of breast (25), ovarian cancer (26), hepatocellular carcinoma (26), cervical cancer $(27,28)$, and lung carcinoma cells (29) and human umbilical vein endothelial cells (28). However, the $\mathrm{IC}_{50}$ value is higher in normal cells, meaning that the drug can be used to prevent the proliferation of cancer cells at a lower concentration, without a strong effect on normal cells. In addition, the in vivo and in vitro therapeutic efficacy of RHL on human glioma have not been evaluated. As known, human glioma U87 xenografts are useful models for testing the therapeutic effects of antitumor agents in vivo (31-33). Human glioma U87 cells and a xenograft model in BALB/c nude mice were used to examine the antitumor activity of RHL against human glioma in the present study. RHL exerted a significant inhibitory effect on the growth of human glioma U87 xenografts in BALB/c nude mice. There was no significant body weight loss in the treated groups compared with the control group. All animals survived the duration of the experiment. The results indicate that RHL shows a high efficacy against human glioma U87 cells.

RHL showed a potent cytotoxic effect on U87 cells. In the cell proliferation assays, RHL $(160 \mu \mathrm{mol} / \mathrm{l})$ inhibited U87 cell proliferation by $40 \%$ at $48 \mathrm{~h}$ (Fig. 2A). In the cell growth curve assays, RHL at concentrations of 80 and $160 \mu \mathrm{mol} / 1$ inhibited U87 cell proliferation from the initial administration (Fig. 2B). In the cell apoptosis assays, RHL displayed a highly potent apoptosis-inducing effect on the U87 cells. It is evident that the induction of apoptosis appeared to be the predominant mode of RHL-induced cell death particularly in the high dose-RHL group $(160 \mu \mathrm{mol} / \mathrm{l})$.

Excessive intracellular ROS production induced by a toxicant within the mitochondria or cytoplasm can damage many types of biological macromolecules such as membrane lipids, DNA and enzymes. Furthermore, ROS induce mitochondrial depolarization and permeability transition $(34,35)$. In the present study, the DCF fluorescence assay showed that the intracellular ROS level in the RHL-treated cells was higher than that of the control cells. This observation suggests that RHL exposure caused oxidative stress, mitochondrial permeability transition, and apoptosis of U87 cells. Therefore, excessive ROS induction by RHL exposure may be a key early factor in the cellular damage and apoptosis of U87 cells.

As known, members of the Bcl-2 protein family act as key regulators of cellular apoptosis and are important determinants of cellular sensitivity or resistance to chemotherapy drugs (36-38). Overexpression of Bcl-2, an anti-apoptotic member of this family, is commonly observed in human cancers, and Bcl-2 overexpression correlates with chemoresistance in this disease. The anti-apoptotic protein, Bcl-2, has been associated with inhibition of apoptosis and cell survival mechanisms. The Bax and Bim proteins are pro-apoptotic members of this family, and their increased expression is often associated with increased apoptosis in target cells $(39,40)$. Next, we studied the molecular mechanism of apoptosis induced by RHL in human glioma U87 cells. As shown in Fig. 5, when the U87 cells were treated with RHL for $48 \mathrm{~h}$, levels of Bax and Bim proteins were significantly upregulated compared with 
the control group in a dose-dependent manner. In contrast, compared with the control group, the level of Bcl-2 protein in the cells treated with RHL was significantly downregulated in a dose-dependent manner. Furthermore, the level of cyclin D1 was decreased in the RHL group in a dose-dependent manner. Cyclin D1 is a protein required for progression through the G1 phase of the cell cycle. During the G1 phase, it is synthesized rapidly and accumulates in the nucleus, and is degraded as the cell enters the S phase. Cyclin D1 is a regulatory subunit of cyclin-dependent kinases CDK4 and CDK6. The protein dimerizes with CDK4/6 to regulate G1/S phase transition and entry into the $\mathrm{S}$ phase (41). It can be concluded that RHL also inhibited cell proliferation by blocking the G1/S phase of the cell cycle.

Our results showed that RHL is highly effective against the growth of human glioma U87 xenografts in BALB/c nude mice. In vitro, RHL induced apoptosis in human glioma U87 cells by decreasing Bcl-2 and increasing the expression of BAX and Bim. The downregulation of the level of cyclin D was also involved in the anticancer effects of RHL.

\section{Acknowledgements}

The present study was supported by grants from the National Natural Science Foundation of China (81001439), and the General Program of the Natural Science Foundation of Hebei Province of China (H2012401030).

\section{References}

1. Gao J, Wang Z, Liu H, Wang L and Huang G: Liposome encapsulated of temozolomide for the treatment of glioma tumor: Preparation, characterization and evaluation. Drug Discov Ther 9: 205-212, 2015.

2. Kawaji H, Tokuyama T, Yamasaki T, Amano S, Sakai N and Namba H: Interferon- $\beta$ and temozolomide combination therapy for temozolomide monotherapy-refractory malignant gliomas. Mol Clin Oncol 3: 909-913, 2015.

3. Yu Z, Xie G, Zhou G, Cheng Y, Zhang G, Yao G, Chen Y, Li Y and Zhao G: NVP-BEZ235, a novel dual PI3K-mTOR inhibitor displays anti-glioma activity and reduces chemoresistance to temozolomide in human glioma cells. Cancer Lett 367: 58-68, 2015.

4. Wang X, Jia L, Jin X, Liu Q, Cao W, Gao X, Yang M and Sun B: NF- $\mathrm{KB}$ inhibitor reverses temozolomide resistance in human glioma TR/U251 cells. Oncol Lett 9: 2586-2590, 2015.

5. Tian T, Li A, Lu H, Luo R, Zhang M and Li Z: TAZ promotes temozolomide resistance by upregulating MCL-1 in human glioma cells. Biochem Biophys Res Commun 463: 638-643, 2015.

6. Zhou Q: BMS-536924, an ATP-competitive IGF-1R/IR inhibitor, decreases viability and migration of temozolomide-resistant glioma cells in vitro and suppresses tumor growth in vivo. Onco Targets Ther 8: 689-697, 2015.

7. Huang Q, Lu G, Shen HM, Chung MC and Ong CN: Anti-cancer properties of anthraquinones from rhubarb. Med Res Rev 27: 609-630, 2007.

8. Tamura T, Yokoyama $\mathrm{T}$ and Ohmori K: Effects of diacerein on indomethacin-induced gastric ulceration. Pharmacology 63 : 228-233, 2001.

9. Zhong XF, Huang GD, Luo T, Deng ZY and Hu JN: Protective effect of rhein against oxidative stress-related endothelial cell injury. Mol Med Rep 5: 1261-1266, 2012.

10. Zhao YL, Zhou GD, Yang HB, Wang JB, Shan LM, Li RS and Xiao XH: Rhein protects against acetaminophen-induced hepatic and renal toxicity. Food Chem Toxicol 49: 1705-1710, 2011.

11. Hu G, Liu J, Zhen YZ, Wei J, Qiao Y, Lin YJ and Tu P: Rhein inhibits the expression of vascular cell adhesion molecule 1 in human umbilical vein endothelial cells with or without lipopolysaccharide stimulation. Am J Chin Med 41: 473-485, 2013.
12. Cong XD, Ding MJ, Dai DZ, Wu Y, Zhang Y and Dai Y: ER stress, p66shc, and p-Akt/Akt mediate adjuvant-induced inflammation, which is blunted by argirein, a supermolecule and rhein in rats. Inflammation 35: 1031-1040, 2012.

13. Barnard DL, Huffman JH, Morris JL, Wood SG, Hughes BG and Sidwell RW: Evaluation of the antiviral activity of anthraquinones, anthrones and anthraquinone derivatives against human cytomegalovirus. Antiviral Res 17: 63-77, 1992.

14. Cyong J, Matsumoto T, Arakawa K, Kiyohara H, Yamada H and Otsuka Y: Anti-bacteroides fragilis substance from rhubarb. J Ethnopharmacol 19: 279-283, 1987.

15. Agarwal SK, Singh SS, Verma S and Kumar S: Antifungal activity of anthraquinone derivatives from Rheum emodi. J Ethnopharmacol 72: 43-46, 2000.

16. Singh B, Nadkarni JR, Vishwakarma RA, Bharate SB, Nivsarkar $M$ and Anandjiwala S: The hydroalcoholic extract of Cassia alata (Linn.) leaves and its major compound rhein exhibits antiallergic activity via mast cell stabilization and lipoxygenase inhibition. J Ethnopharmacol 141: 469-473, 2012.

17. Lin ML, Chung JG, Lu YC, Yang CY and Chen SS: Rhein inhibits invasion and migration of human nasopharyngeal carcinoma cells in vitro by down-regulation of matrix metalloproteinases-9 and vascular endothelial growth factor. Oral Oncol 45: 531-537, 2009.

18. Fernand VE, Losso JN, Truax RE, Villar EE, Bwambok DK, Fakayode SO, Lowry M and Warner IM: Rhein inhibits angiogenesis and the viability of hormone-dependent and -independent cancer cells under normoxic or hypoxic conditions in vitro. Chem Biol Interact 192: 220-232, 2011.

19. Chen YY, Chiang SY, Lin JG, Ma YS, Liao CL, Weng SW, Lai TY and Chung JG: Emodin, aloe-emodin and rhein inhibit migration and invasion in human tongue cancer SCC-4 cells through the inhibition of gene expression of matrix metalloproteinase-9. Int J Oncol 36: 1113-1120, 2010.

20. Shi P, Huang $Z$ and Chen G: Rhein induces apoptosis and cell cycle arrest in human hepatocellular carcinoma BEL-7402 cells. Am J Chin Med 36: 805-813, 2008.

21. Hsia TC, Yang JS, Chen GW, Chiu TH, Lu HF, Yang MD, Yu FS, Liu KC, Lai KC, Lin CC, et al: The roles of endoplasmic reticulum stress and $\mathrm{Ca}^{2+}$ on rhein-induced apoptosis in A-549 human lung cancer cells. Anticancer Res 29: 309-318, 2009.

22. Tsang SW and Bian ZX: Anti-fibrotic and anti-tumorigenic effects of rhein, a natural anthraquinone derivative, in mammalian stellate and carcinoma cells. Phytother Res 29: 407-414, 2015.

23. Huang HJ, Lin CC, Chou HC, Chen YW, Lin ST, Lin YC, Lin DY, Lyu KW and Chan HL: Proteomic analysis of rheininduced cyt: ER stress mediates cell death in breast cancer cells. Mol Biosyst 10: 3086-3100, 2014.

24. Du Q, Bian XL, Xu XL, Zhu B, Yu B and Zhai Q: Role of mitochondrial permeability transition in human hepatocellular carcinoma Hep-G2 cell death induced by rhein. Fitoterapia 91: 68-73, 2013.

25. Lin YJ and Zhen YS: Rhein lysinate suppresses the growth of breast cancer cells and potentiates the inhibitory effect of Taxol in athymic mice. Anticancer Drugs 20: 65-72, 2009.

26. Lin YJ, Zhen YZ, Shang BY and Zhen YS: Rhein lysinate suppresses the growth of tumor cells and increases the anti-tumor activity of Taxol in mice. Am J Chin Med 37: 923-931, 2009.

27. Zhen YZ, Lin YJ, Gao JL, Zhao YF and Xu AJ: Rhein lysinate inhibits cell growth by modulating various mitogen-activated protein kinases in cervical cancer cells. Oncol Lett 2: 129-133, 2011.

28. Lin YJ, Zhen YZ, Zhao YF, Wei J and Hu G: Rhein lysinate induced S-phase arrest and increased the anti-tumor activity of 5-FU in HeLa cells. Am J Chin Med 39: 817-825, 2011.

29. Zhen YZ, Hu G, Zhao YF, Yan F, Li R, Gao JL and Lin YJ: Synergy of Taxol and rhein lysinate associated with the downregulation of ERK activation in lung carcinoma cells. Oncol Lett 6: 525-528, 2013.

30. Reardon DA, Galanis E, DeGroot JF, Cloughesy TF, Wefel JS, Lamborn KR, Lassman AB, Gilbert MR, Sampson JH, Wick W, et al: Clinical trial end points for high-grade glioma: The evolving landscape. Neuro-oncol 13: 353-361, 2011.

31. Chastagner P, Sudour H, Mriouah J, Barberi-Heyob M, BernierChastagner V and Pinel S: Preclinical studies of pegylated- and non-pegylated liposomal forms of doxorubicin as radiosensitizer on orthotopic high-grade glioma xenografts. Pharm Res 32: 158-166, 2015. 
32. Li XQ, Ouyang ZG, Zhang SH, Liu H, Shang Y, Li Y and Zhen YS: Synergistic inhibition of angiogenesis and glioma cellinduced angiogenesis by the combination of temozolomide and enediyne antibiotic lidamycin. Cancer Biol Ther 15: 398-408, 2014.

33. Zhang L and Zhao D: Liposomal encapsulation enhances in vivo near infrared imaging of exposed phosphatidylserine in a mouse glioma model. Molecules 18: 14613-14628, 2013

34. Polunas M, Halladay A, Tjalkens RB, Philbert MA, Lowndes $H$ and Reuhl K: Role of oxidative stress and the mitochondrial permeability transition in methylmercury cytotoxicity. Neurotoxicology 32: 526-534, 2011.

35. Li JP: Resveratrol caused apoptosis in QGY-7701 cells. Eur Rev Med Pharmacol Sci 19: 3303-3308, 2015.

36. Ma YX, Guo Z and Sun T: CGRP inhibits norepinephrine induced apoptosis with restoration of $\mathrm{Bcl}-2 / \mathrm{Bax}$ in cultured cardiomyocytes of rat. Neurosci Lett 549: 130-134, 2013.

37. Zeng C, Ke Z, Song Y, Yao Y, Hu X, Zhang M, Li H and Yin J: Annexin A3 is associated with a poor prognosis in breast cancer and participates in the modulation of apoptosis in vitro by affecting the Bcl-2/Bax balance. Exp Mol Pathol 95: 23-31, 2013.
38. Reed JC, Miyashita T, Takayama S, Wang HG, Sato T, Krajewski S, Aimé-Sempé C, Bodrug S, Kitada S and Hanada M: BCL-2 family proteins: Regulators of cell death involved in the pathogenesis of cancer and resistance to therapy. J Cell Biochem 60: 23-32, 1996.

39. Labi V, Woess C, Tuzlak S, Erlacher M, Bouillet P, Strasser A, Tzankov A and Villunger A: Deregulated cell death and lymphocyte homeostasis cause premature lethality in mice lacking the BH3-only proteins Bim and Bmf. Blood 123: 2652-2662, 2014.

40. Youle RJ and Strasser A: The BCL-2 protein family: Opposing activities that mediate cell death. Nat Rev Mol Cell Biol 9: 47-59, 2008.

41. Baldin V, Lukas J, Marcote MJ, Pagano M and Draetta G: Cyclin D1 is a nuclear protein required for cell cycle progression in G1. Genes Dev 7: 812-821, 1993. 